\title{
EVALUASI SISTEM PELAYANAN TERPADU KECAMATAN JAMBI TIMUR MENGGUNAKAN KERANGKA KERJA COBIT 5 PADA DOMAIN DELIVER, SERVICE AND SUPPORT
}

\author{
$\underline{\text { Redo Hermawan }}{ }^{1}$, M. Riza Pahlevi ${ }^{2}$ \\ Program Studi Magister Sistem Informasi, STIKOM Dinamika Bangsa, Jambi \\ Jl. Jendral Sudirman, Kec. The Hok, (0741) 35095 \\ E-mail: reddohermawan@gmail.com ${ }^{l}$,rizapahlevi@stikom-db.ac.id ${ }^{2}$
}

\begin{abstract}
Jambi Timur District has implemented a computerized integrated service system in its business process. However, there is no guarantee that the implemented system is said to be good. Therefore, an evaluation is being required to measure the extent of the process in the Jambi Timur District. COBIT 5 is an IT governance framework consisting of 37 processes that are loaded into four domains. One of the domains is Deliver, Service and Support which discusses how IT is implemented., The overall DSS domain assessment has reached level 3 while the expectations of stakeholders in some processes is level 4 , which means there is a gap as much as one level. Based on the results of the study, recommendations for improvements were made to improve IT services and utilization in Jambi Timur District.
\end{abstract}

Keywords:IT, COBIT, DSS, Integrated Service System

\begin{abstract}
Abstrak
Kecamatan Jambi Timur telah mengimplementasikan sistem pelayanan terpadu yang terkomputerisasi dalam proses bisnisnya. Meski demikian, belum ada jaminan bahwa sistem yang berjalan sudah dikatakan baik. Maka dari itu, perlu diadakan evaluasi untuk mengukur sudah sejauh mana proses yang ada di Kecamatan Jambi Timur. COBIT 5 adalah kerangka kerja tata kelola TI yang terdiri dari 37 proses yang dimuat ke dalam empat domain. Salah satu domainnya adalah Deliver, Service and Support yang membahas bagaimana penerapan TI berjalan. Penilaian domain DSS secara keseluruhan sudah mencapai level 3 sedangkan harapan stakeholder di beberapa proses adalah 4 yang berarti ada kesenjangan sebanyak satu level. Berdasarkan hasil penelitian, disusun rekomendasi-rekomendasi perbaikan untuk meningkatkan pelayanan dan pemanfaatan TI di Kecamatan Jambi Timur.
\end{abstract}

Kata kunci: TI, COBIT, DSS, Sistem Pelayanan Terpadu

(c) 2019 Jurnal Manajemen Sistem Informasi.

\section{Pendahuluan}

Pada dewasa ini penerepan sistem informasi dalam penunjang kehidupan sehari-hari tidak dapat terelakkan. Hal ini juga berlaku dalam bidang pelayanan di sebuah organisasi baik swasta mau pun pemerintahan. Pelayanan yang cepat, akurat dan efisienakan sangat membantu organisasi dalam melakukan proses bisnis yang berjalan.

Salah satu praktik tata kelola teknologi informasi yang dapat dilakukan adalah dengan melakukan evaluasi sumber daya teknologi informasi atau sistem informasi. Evaluasi bertujuan untuk menilai,

Jurnal Manajemen Sistem Informasi Vol.4, No.2, Juni 2019 
memonitor, dan memastikan bahwa sumber daya layanan mampu beroperasi secara efektif sesuai dengan SOP. Evaluasi penerapan sistem informasi dalam sebuah organisasi sering kali dipandang sebelah mata, padahal keberhasilan mekanisme yang baik tercipta melalui evaluasi yang diterapkan secara maksimal pada keberlangsungan kinerja di suatu organisasi.

COBIT adalah kerangka kerja tata kelola teknologi informasi dan perangkat pendukung yang memungkinkan manajer untuk menjembatani kesenjangan antara tujuan bisnis, masalah teknis, dan risiko bisnis. COBIT memungkinkan pengembangan kebijakan yang jelas dan praktik yang baik untuk kontrol TI di seluruh perusahaan.COBIT menekankan kepatuhan terhadap peraturan, membantu perusahaan meningkatkan nilai yang diperoleh dari TI, memungkinkan penyelarasan dan memberikan panduan sederhana tentang implementasi kerangka COBIT ${ }^{[5]}$

Kantor Kecamatan Jambi Timur yang terletak di Jalan Amangkurat No.I Jambi Timur, Kota Jambi telah mengimplementasikan teknologi informasi berupa pelayanan terpadu yaitu PATEN (Pelayanan Administrasi Terpadu Kecamatan) sesuai Permendagri Nomor 4 Tahun 2010 yang meliputi pelayanan bidang perizinan dan non-perizinan ${ }^{[8]}$. Meski pun teknologi informasi di Kantor Kecamatan Jambi Timur telah dimanfaatkan dan mendukung aktivitas dan proses bisnis yang ada, bukan jaminan pengimplementasiannya menggunakan tata kelola TI dengan efektif dan efisien.

Maka dari itu, perlu adanya evaluasi terhadap sistem pelayanan terpadu di kantor Kecamatan Jambi Timur menggunakan kerangka kerja COBIT 5 yang nantinya terfokus pada domain Deliver, Service dan Support (DSS). Dalam penelitian ini nantinya akan menghasilkan evaluasi serta rekomendasi yang dapat menjadi bahan pertimbangan untuk pengembangan kualitas pelayanan ke depannya.

Berdasarkan masalah yang penulis uraikan, maka penulis tertarik untuk melakukan penelitian yang berjudul "Evaluasi Sistem Pelayanan Terpadu Kecamatan Jambi Timur Menggunakan Kerangka Kerja COBIT 5 pada DomainDeliver, Service,Support".

Berdasarkan latar belakang masalah di atas, maka penulis merumuskan masalah sebagai berikut: (a) Sejauh mana tingkat kapabilitas penerapan sistem pelayanan terpadu pada domain Deliver, Service dan Support di kantor Kecamatan Jambi Timur? (b) Bagaimana kondisi tata kelola TI sistem pelayanan terpadu di kantor Kecamatan Jambi Timur yang sekarang (as is) dengan yang diharapkan (to be) pada domain Deliver, Service and Support? Penelitian ini bertujuan untuk mengevaluasi sistem pelayanan terpadu di kantor Kecamatan Jambi Timur dengan COBIT 5 pada domain DSS yang nantinya akan menghasilkan rekomendasi. Ada pun manfaat penelitian ini diharapkan dapat menjadi bahan pertimbangan untuk Kecamatan Jambi Timur sebagai peningkatan pelayanan.

\section{Tinjauan Pustaka}

Dalam penelitian yang dilakukan Abdul Hakim dan kawan-kawan yang berjudul " Evaluasi Tata Kelola Teknologi Informasi dengan Framework COBIT 5 di Kementerian ESDM (Studi Kasus Pada Pusat Data Dan Teknologi Informasi ESDM)" menunjukkan pengumpulan data dilakukan dengan metode wawancara, kuesioner dan observasi yang berbeda dengan penelitian ini yang hanya menggunakan metode kuesioner. Di penelitian tersebut tidak hanya berfokus pada satu domain tetapi empat domain yaitu APO, DSS, MEA dan EDM ${ }^{[2]}$.

Penelitian tata kelola TI yang menggunakan kerangka kerja COBIT 5 yang disusun oleh Guido Waluyan dan kawan-kawan yang berjudul "Evaluasi Kinerja Tata Kelola TI Terhadap Penerapan Sistem Informasi Starclick Framework COBIT 5 (Studi Kasus: PT. Telekomunikasi Indonesia, Tbk Semarang)" menggunakan metode deskriptif kualitatif di mana hasil pengumpulan data dideskripsikan berdasarkan perspektif narasumber dengan memperhatikan kondisi riil di lapangan [9].

Metode yang digunakan dalam penelitian I Gusti Lanang Agung Raditya Putra dan kawan-kawan dalam penelitian "Evaluasi Tata Kelola Sistem Informasi Akademik Berbasis COBIT 5 di Universitas Pendidikan Ganesha" adalah metode campuran kuantitatif dan kualitatif menggunakan instrumen kuesioner, wawancara, dan studi dokumen. Fokus penelitian ini pada beberapa domain COBIT 5 meliputi, EDM4, APO7, dan BAI4 yang berarti penelitian tersebut hanya menggunakan tiga proses COBIT 5. Sumber data di penelitian diperoleh dari Kepala Pusat Komputer (Puskom), staf TI Puskom, staf TI fakultas, dan pembantu dekan I. Analisis penelitian dilakukan dengan cara deskriptif interpretatif berbasis COBIT 5 [3].

Galih Yudha Saputra dan kawan-kawan dalam penelitiannya "Pengukuran Kinerja Sistem Teknologi Informasi E-KTP Pada Kantor Kecamatan Pakis Kabupaten Malang Menggunakan Framework COBIT" menggunakan metode innitation sesuai PAM COBIT 5 dan kuesioner. Di dalam penelitian tersebut menggunakan proses DSS01 Manage Operations. Di penelitian tersebut juga menggunakan Skala Guttman seperti di penelitian ini ${ }^{[4]}$. 
Rininta Ayuningdiah dalam penelitiannya "Pengukuran Tingkat Kapabilitas Tatakelola TI Menggunakan Kerangka kerja COBIT 5 (Studi Kasus: PT. PDA. Net Kota Cirebon)" menggunakan metode wawancara dan observasi. Penentuan domain dalam penelitian tersebut menggunakan pemetaan antara IT Related Goals COBIT 5 dengan visi misi organisasi ${ }^{[1]}$.

Dari tinjauan pustaka di atas dapat diambil kesimpulan perbedaan dan persamaan dengan penelitian ini, yaitu: dalam penelitian ini hanya menggunakan metode kuesioner berbeda dengan penelitian di atas yang memakai metode seperti observasi dan wawancara, dalam peneltian ini menggunakan semua proses yang ada di domain DSS, penelitian yang dilakukan penulis menggunakan Skala Guttman sama halnya dengan yang dilakukan oleh Galih Yudha Saputra dan kawan-kawan.

\section{Metodologi}

\subsection{Alur Penelitian}

Tahapan dalam penulisan ini dimulai dari identifikasi masalah dan studi literatur yang dilaksanakan selama dua bulan. Kemudian di tahap kedua, tahap di mana penulis melakukan analisis dan pengumpulan data yang kurang lebih akan dilaksanakan selambatnya tiga bulan. Tahap ketiga merupakan pembuatan rekomendasi dari analisis dari temuan pada tahapan sebelumnya juga membuat kesimpulan dari temuan yang didapat di mana akan dilaksanakan selama satu sampai dua bulan. Ada pun kegiatan tersebut akan dijabarkan sebagai berikut:

1. Identifikasi Masalah. Pada tahapan ini dilakukan penggalian informasi seputar pelayanan yang ada pada Kecamatan Jambi Timur untuk mengetahui masalah-masalah yang ada.

2. Studi Literatur. Pada bagian ini penulis melakukan ulasan dan studi mengenai COBIT 5 terutama domain DSS untuk meningkatkan pemahaman pada topik penelitian juga melakukan peninjauan pustaka pada penelitian sejenis untuk memperoleh gambaran pada konteks penelitian yang berbeda

3. Analisis RACI Chart. Pada tahapan ini penulis menggunakan tabel RACI Chart pada domain DSS di COBIT 5 untuk mengidentifikasi siapa yang akan menjadi responden dalam penelitian. Bahan pada tahap ini adalah struktur organisasi Kecamatan Jambi Timur

4. Pengumpulan Data. Pengumpulan data pada penelitian ini menggunakan kuesioner yang akan disebarkan ke responden yang telah dianalisis dengan RACI Chart.

5. Analisis Capability Model. Pada tahapan ini penulis mengukur sudah sejauh mana kemampuan proses di pelayanan Kecamatan Jambi Timur menggunakan Process Capability Model di COBIT 5. Bahan pada tahap ini adalah kuesioner yang telah diisi oleh responden.

6. Analisis Gap. Setelah didapat kemampuan proses lalu penulis menganalisis kesenjangan sistem pelayanan terpadu di kantor Kecamatan Jambi Timur yang sekarang (as in) dengan yang diharapkan (to be) pada domain Deliver, Service dan Support.

7. Membuat Rekomendasi dan Kesimpulan. Setelah mengetahui gap, dan temuan di pelayanan Kecamatan Jambi Timur pada domain DSS, kemudian penulis melakukan rekomendasi yang diharapkan dapat menjadi acuan dalam mengambil keputusan untuk ke depannya serta membuat kesimpulan dari penelitian.

8. Membuat Laporan. Pada tahap ini penyusunan laporan skripsi dikerjakan beriringan dengan dilakukannya dengan tahap-tahap sebelumnya.

\subsection{Metode Pengumpulan Data}

Pada penelitian ini, teknik pengumpulan data yang digunakan adalah kuesioner (angket) yang didistribusikan langsung oleh peneliti kepada responden. Kuesioner (angket) merupakan teknik pengumpulan data yang dilakukan dengan cara memberi seperangkat pertanyaan atau pernyataan tertulis kepada responden untuk dijawabnya ${ }^{[6]}$. Pernyataan pada kuesioner mengacu pada kerangka COBIT 5 di domain DSS, juga skala yang digunakan pada kuesioner disesuaikan dengan level di Capability Model COBIT 5 yaitu 0 sampai 5 .

\section{Pembahasan}

\subsection{Gambaran Umum Sistem Pelayanan}

Sebagai tempat pelayanan masyarakat, sistem informasi di kecamatan sangat menopang keberlangsungan proses, terutama proses perizinan dan persuratan. 
Sistem pelayanan terpadu Kecamatan Jambi Timur dibawahi oleh Seksi Pelayanan Umum merupakan layanan terkomputerisasi dan bersifat daring yang membantu masyarakat untuk mempermudah proses di bidang perizinan dan non-perizinan. Sistem pelayanan ini memiliki tiga produk utama yaitu situs web kecjambitimur.jambikota.go.id yang berisi profil, visi-misi, informasi dan berita di Kecamatan Jambi Timur, e-pelayanan yang membantu pengurusan perizinan di kecamatan dan e-yankel dengan fitur yang sama tetapi untuk di kelurahan. Selain dapat mengurus perizinan lewat dua layanan tadi, masyarakat juga dapat mengunjungi langsung kantor kecamatan untuk memproses perizinan. Berikut di bawah ini merupakan tangkapan layar web, e-pelayanan, dan e-yankel:

\subsection{Pemetaan RACI Chart}

RACI Chart adalah diagram matriks untuk seluruh aktivitas atau otorisasi keputusan yang harus diambil dalam suatu organisasi yang dikaitkan dengan seluruh pihak atau posisi yang terlibat. Diagram RACI digunakan dalam proses pemetaan pihak-pihak yang terkait dan bertanggungjawab dengan tepat dalam sebuah organisasi ${ }^{[7]}$.RACI merupakan singkatan dari Responsible, Accountable, Consulted, dan Informed yang makna singkatan tersebut dapat dijabarkan sebagai:

1. Responsible adalah orang yang melakukan pekerjaan untuk diselesaikan.

2. Accountable adalah orang yang memiliki otoritas dan tanggung jawab untuk memutuskan perkara orang-orang berstatus Responsible.

3. Consulted adalah orang yang berkontribusi memberikan saran atau umpan balik di organisasi.

4. Informed adalah orang yang selalu harus mengetahui sudah sampai mana kemajuan sebuah tugas.

Tabel 1 Pemetaan Stakeholder Kecamatan Jambi Timurr dengan RACI Chart DSS

$\begin{array}{ccc}\begin{array}{c}\text { Fungsional Struktur } \\ \text { Diagram RACI }\end{array} & \begin{array}{c}\text { Fungsional Struktur } \\ \text { Kecamatan Jambi Timur }\end{array} & \begin{array}{c}\text { Praktik-praktik pada } \\ \text { Domain DSS }\end{array}\end{array}$

\begin{tabular}{ccc}
\hline Chief Executive Officer & Camat Jambi Timur & DSS06.01, DSS06.02 \\
\hline \multirow{3}{*}{ Chief Operating Officer } & Sekretaris Camat & DSS01.03, DSS04.01, \\
& & DSS04.02, DSS04.05, \\
& DSS06.01, DSS06.02
\end{tabular}

\begin{tabular}{ccc}
\hline Chief Financial Officer & Sub-bagian Perancanaan dan \\
Keuangan & DSS05.01, DSS06.01, \\
Committee & DSS06.02, DSS06.03 \\
\hline Head Human Resources & Sub-bagian Umum dan & \\
\hline $\begin{array}{c}\text { Strategy Executive } \\
\text { Committee }\end{array}$ & Kepegawaian & DSS04.03, DSS04.04, \\
& & DSS05.01, DSS05.03, \\
& & DSS06.03 \\
\hline
\end{tabular}

Business Process Owner

Business Executive

Seksi Pelayanan Umum

DSS01.03, DSS01.04, DSS01.05, DSS02.01, DSS02.02, DSS02.03, DSS02.04, DSS02.05, DSS02.06, DSS02.07, DSS03.01, DSS03.04, DSS03.05, DSS04.01, DSS04.02, DSS04.03, DSS04.04, DSS04.05, DSS04.06, DSS04.08, DSS05.01, DSS05.02, DSS05.03, DSS05.04, Audit DSS05.05, DSS05.07, DSS06.01, DSS06.02, DSS06.03, DSS06.04, DSS06.05, DSS06.06. 


\subsection{Capability Level}

Di bawah ini adalah persamaan capability level pada setiap responden dan rata-rata capability level keseluruhan pada setiap praktik.

1. Menghitung Capability Level pada setiap responden

$$
\mathrm{CL} \mathbf{i}=\mathrm{NL} 0+\mathrm{NL} 1+\mathrm{NL2}+\mathrm{NL} 3+\mathrm{NL} 4+\mathrm{NL5}
$$

Keterangan:

$\mathrm{CLi}=\quad$ Nilai capability level untuk setiap responden dalam setiap proses

domain.

$\mathrm{NLO}=\quad$ Nilai normalisasi level pada level 0

NL1 = Nilai normalisasi level pada level 1

$\mathrm{NL} 2=\quad$ Nilai normalisasi level pada level 2

$\mathrm{NL3}=\quad$ Nilai normalisasi level pada level 3

NL4 $=\quad$ Nilai normalisasi level pada level 4

NL5 = Nilai normalisasi level pada level 5

2. Menghitung Rata-rata Capability Level Keseluruhan di setiap practice

$$
\mathrm{CLa} \frac{\sum \mathrm{CL}_{1}}{\Sigma \mathrm{R}}
$$

Keterangan:

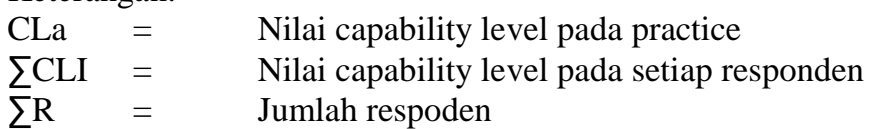

Untuk hasil perhitungan capability level pada setiap responden dan rata-rata capability level keseluruhan pada setiap practice dapat dilihat di tabel berikut:

\begin{tabular}{|c|c|c|c|c|c|c|c|c|c|}
\hline \multirow{2}{*}{ Proses } & \multicolumn{8}{|c|}{ Practice } & \multirow{2}{*}{$\begin{array}{l}\text { Rata- } \\
\text { rata }\end{array}$} \\
\hline & .01 & \multicolumn{2}{|c|}{.02} & 03 & \multicolumn{2}{|r|}{.04} & \multicolumn{2}{|c|}{.05} & \\
\hline $\begin{array}{c}\text { DSS01 Manage } \\
\text { Operations }\end{array}$ & 3 & \multicolumn{2}{|c|}{2,5} &, 25 & \multicolumn{2}{|r|}{3,33} & \multicolumn{2}{|c|}{3,33} & 3,08 \\
\hline \multirow{2}{*}{ Proses } & \multicolumn{8}{|c|}{ Practice } & \multirow{2}{*}{$\begin{array}{c}\text { Rata- } \\
\text { rata }\end{array}$} \\
\hline & .01 & .02 & \multicolumn{3}{|c|}{.04} & .05 & .06 & .07 & \\
\hline \multirow{2}{*}{$\begin{array}{l}\text { DSS02 Manage } \\
\text { Service Request } \\
\text { and Incidents }\end{array}$} & & \multirow[b]{2}{*}{3} & \multirow[b]{2}{*}{3,33} & \multirow{2}{*}{\multicolumn{2}{|c|}{3}} & & & \multirow[b]{2}{*}{2,66} & \multirow[b]{2}{*}{2,74} \\
\hline & 2.6 & & & & & 2,33 & 2,33 & & \\
\hline \multirow{2}{*}{ Proses } & \multicolumn{8}{|c|}{ Practice } & \multirow{2}{*}{$\begin{array}{l}\text { Rata- } \\
\text { rata }\end{array}$} \\
\hline & .01 & \multicolumn{2}{|c|}{.02} & \multicolumn{2}{|c|}{.03} & .04 & \multicolumn{2}{|r|}{.05} & \\
\hline $\begin{array}{c}\text { DSS03 Manage } \\
\text { Problems }\end{array}$ & 2,66 & \multicolumn{2}{|r|}{3} & \multicolumn{2}{|c|}{2,5} & 3,33 & \multicolumn{2}{|r|}{3} & 2,90 \\
\hline \multirow{2}{*}{ Proses } & \multicolumn{8}{|c|}{ Practice } & \multirow{2}{*}{$\begin{array}{l}\text { Rata- } \\
\text { rata }\end{array}$} \\
\hline & .01 & .02 & .03 & .04 & .05 & .06 & .07 & .08 & \\
\hline DSS04 & 2.5 & 3.25 & 2,25 & 3 & 2,75 & 2,6 & 3 & 2,66 & 2,75 \\
\hline Manage & & & & & & & & & \\
\hline
\end{tabular}

Tabel 2 Nilai Capability tiap Practice 
Continuity

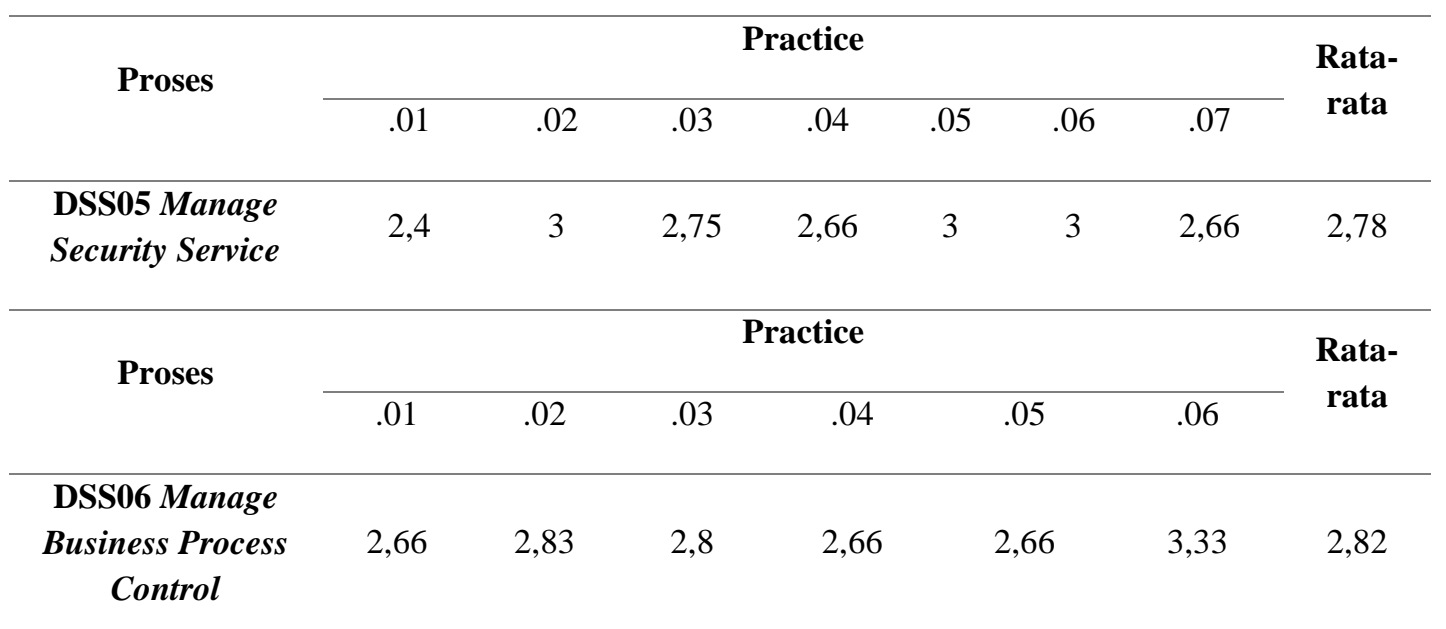

Tabel di bawah menunjukkan capability pada setiap proses di domain DSS. Hasil perhitungan didapat dari hasil raya-rata di semua practice dalam satu proses domain DSS. Nilai. Berikut merupakan capability level pada setiap proses DSS:

Tabel 3 Capability Level

\begin{tabular}{ccc}
\hline & Tabel 3 Capability Level & As Is \\
\hline $\begin{array}{c}\text { NSS01 Manage } \\
\text { Operations }\end{array}$ & 3,08 & 3 \\
\hline $\begin{array}{c}\text { DSS02 Manage } \\
\text { Service Request and } \\
\text { Incidents }\end{array}$ & 2,74 & 3 \\
\hline $\begin{array}{c}\text { DSS03 Manage } \\
\text { Problems }\end{array}$ & 2,90 & 3 \\
\hline $\begin{array}{c}\text { DSS04 } \\
\text { Manage Continuity }\end{array}$ & 2,75 & 3 \\
\hline $\begin{array}{c}\text { DSS05 Manage } \\
\text { Security Service }\end{array}$ & \\
\hline $\begin{array}{c}\text { DSS06 Manage } \\
\text { Business Process } \\
\text { Control }\end{array}$ & 2,78 & 3 \\
\hline Rata-rata & 2,82 & \\
\hline & & 3 \\
\hline
\end{tabular}


Berikut merupakan persamaan tingkat kapabilitas saat ini (as is):

$$
\mathrm{CC}=\frac{\sum \mathrm{CL}_{\mathrm{a}}}{\sum \mathrm{P}_{0}}
$$

$\mathrm{CC}=\quad$ Nilai capability level saat ini.

$\sum \mathrm{CLa}=$ Jumlah keseluruhan nilai capability di semua proses.

$\sum$ Po $=$ Jumlah semua proses.

4.3 Analisis Kesenjangan

Tabel di bawah merupakan rata-rata harapan stakeholder pada setiap proses di domain DSS.

Tabel 4 Harapan Stakeholder

$$
\text { To Be }
$$

Proses

$\begin{array}{llllll}0 & 1 & 2 & 3 & 4 & 5\end{array}$

\section{DSS01 Manage Operations \\ DSS02 Manage Service Request and \\ Incidents}

\section{$\star$} $\star$

\begin{tabular}{l}
\hline DSS03 Manage Problems \\
\hline DSS04 Manage Continuity \\
\hline DSS05 Manage Security Service \\
DSS06 Manage Business Process \\
Control
\end{tabular}

Berdasarkan hasil analisis capability dan harapan maka kesenjangan proses DSS dapat dilihat di gambar berikut:

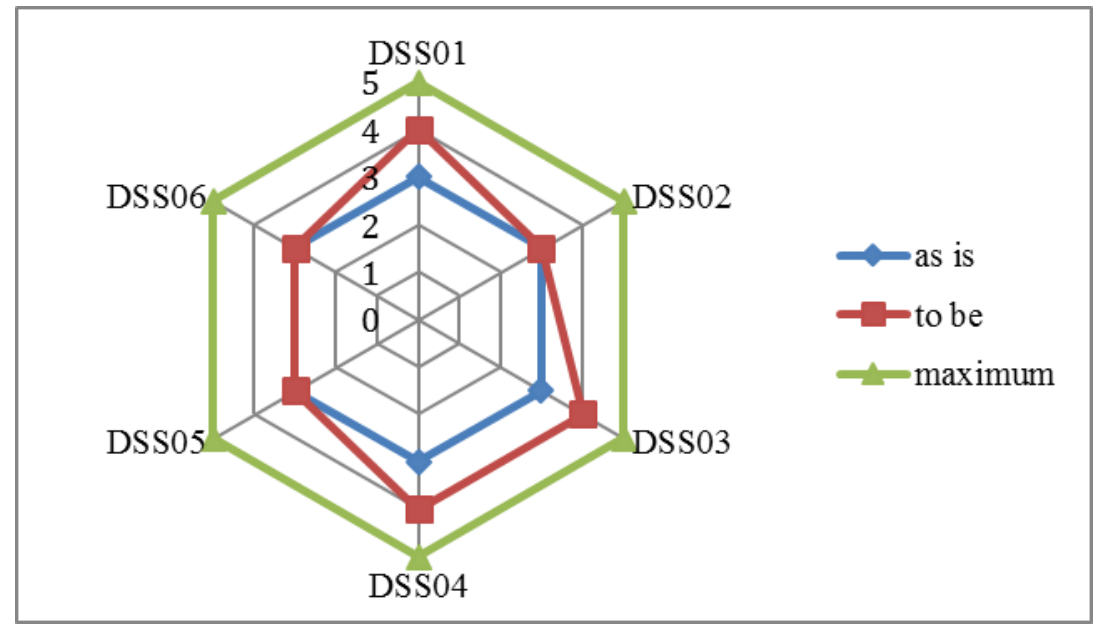

Gambar 1 Kesenjangan Antara Capability dan Harapan Stakeholder

\section{Rekomendasi}

Agar mencapai ke level yang diharapkan pada domain Deliver, Service, and Support, maka disarankan kepada Kecamatan Jambi Timur: 
1. Pada praktik pengelolaan prosedur operasional, untuk melakukan penilaian atau pengukuran pada proses dan SOP yang telah berjalan secara berkala dan terjadwal, membuat batasan-batasan sehingga proses dan SOP di Kecamatan Jambi Timur dapat berjalan dengan stabil.

2. Pada praktik pengelolaan TI dengan pihak ketiga/outsourcing, untuk membuat kebijakan dan kontrak dengan pihak ketiga yang di dalamnya terdapat perjanjian-perjanjian yang telah disetujui kedua pihak dan terdapat batasan-batasan. Mengaudit dan mengasuransikan sumber-sumber TI dari luar atau pihak ketiga secara berkala dan terjadwal dengan batasan-batasan atau SOP.

3. Pada praktik pemonitoran infrastruktur TI, untuk membuat event logs misalnya pada jaringan WiFi Kecamatan Jambi Timur sehingga dapat merekam siapa saja yang masuk dan dapat dimonitor. Mereview event logs secara rutin dan terjadwal, sehingga kejadian-kejadian yang tidak diinginkan dapat dicegah.

4. Pada praktik pengelolaan lingkungan, untuk membuat batasan-batasan di SOP tentang apa saja yang tidak boleh dilakukan di lingkungan tertentu, misalnya dilarang merokok di ruangan TI atau dilarang membawa makanan dan minuman di dekat komputer atau dilarang meletakkan bahan mudah terbakar di dekat perangkat TI. Memasang alarm keamanan dan alat pemadaman api ringan di dekat perangkat dan lingkungan yang rawan munculnya api.

5. Pada praktik pengelolaan fasilitas kantor kecamatan, untuk memastikan kabel-kabel yang terhubung dengan fasilitas TI sudah terlindungi dengan aman dari api atau air. Membuat dokumen struktur perkabelan dan topologi jaringan. Merawat fasilitas TI secara teratur yang dilakukan oleh pihak berwenang.

6. Mengevaluasi kepuasan pengguna terhadap Sistem Pelayanan Kecamatan Jambi Timur secara rutin dan terjadwal.

7. Pada praktik pengelompokan masalah, untuk membuat tingkatan prioritas masalah sehingga asalmuasal masalah diketahui dan dapat diselesaikan secara tepat waktu.

8. Pada praktik pendiagnosisan masalah, untuk menghubungkan tingkatan prioritas yang telah dibuat dengan error-error yang ada di layanan TI.

9. Pada praktik pencatatan error, untuk merekam error-error yang ada untuk untuk dikenali dan dianalisis.

10. Pada praktik penyelesaian masalah, untuk memonitor resolusi masalah dan eror secara berkala agar mengetahui dampaknya pada pelayanan.

11. Pada praktik manajemen masalah, untuk membuat laporan masalah dan error-error yang ada secara rutin dan berkala.

12. Pada praktik penentuan manajemen keberlangsungan bisnis, untuk membuat batasan dalam menerapkan keberlangsungan seperti peran dan tanggung jawab pegawai di organisasi.

13. Pada praktik strategi keberlangsungan, untuk membuat kebijakan waktu minimum untuk pemulihan rencana proses bisnis.

14. Pada praktik penerapan keberlangsungan bisnis,.untuk menentukan/mengidentifikasi tindakan yang akan diambil dalam gangguan rencana proses bisnis. Mengembangkan tindakan tadi ke dalam SOP. Audit tindakan-tindakan tadi secara berkala.

15. Pada praktik pengujian keberlangsungan bisnis, untuk membuat dan melatih peran dan tanggung jawab pegawai dalam keberlangsungan rencana proses bisnis.

16. Pada praktik peningkatan keberlangsungan bisnis, untuk membuat rekomendasi perubahan kebijakan tentang rencana keberlangsungan bisnis sesuai peran dan tanggug jawab secara rutin.

17. Pada praktik pelatihan rencana keberlangsungan, untuk memonitor keahlian dan kompetensi pegawai secara rutin untuk mendukung keberlangsungan rencana proses bisnis.

18. Pada pengelolaan back-up, untuk melakukan pem-back-up-an dengan pihak ketiga secara rutin.

19. Menyusun apa-apa saja yang menjadi kelemahan dalam manajemen rencana keberlangsungan proses bisnis. 
20. Menginstal dan memperbarui software keamanan secara rutin. Mendistribusikan software keamanan secara menyeluruh. Me-review dan memonitor ancaman terhadap TI secara rutin.

\section{Simpulan}

5.1 Kesimpulan

Dalam penelitian ini, penulis melakukan tingkat kapabilitas sistem pelayanan terpadu di Kecamatan Jambi Timur menggunakan kerangka kerja COBIT 5. Proses-proses yang diukur merupakan proses pada domain Deliver, Service and Support (DSS). Pengukuran proses berdasarkan kuesioner yang disebarkan kepada responden di Kecamatan Jambi Timur dengan menggunakan Skala Guttman.

Hasil dari penelitian ini menunjukkan semua proses sudah mengarah ke level tiga dan harapan stakeholder di beberapa proses mengarah ke level empat. Beberapa proses juga sudah sesuai dengan harapan stakeholder yang berarti proses dapat dikatakan baik. Namun, terdapat kesenjangan sebanyak satu level di beberapa proses, adapula practice di sebuah proses seperti DSS04.03 Membangun dan Menerapkan Tanggapan Keberlangsungan Bisnis yang berada pada level 2, sedangkan harapan pada proses DSS04 Mengelola Keberlangsungan secara keseluruhan berada level 4 yang berarti practice tersebut memiliki kesenjangan sebanyak dua tingkat. Berdasarkan kesenjangan yang ditemukan, penelitian ini kemudian membuat rekomendasi-rekomendasi kepada Kecamatan Jambi Timur khususnya di bidang manajemen pelayanan terpadu agar ke depannya dapat digunakan sebagai acuan dalam mengambil keputusan.

\subsection{Saran}

Berdasarkan hasil penelitian yang dilakukan, diharapkan kepada stakeholder Kecamatan Jambi Timur untuk meningkatkan pelayanannya dengan menjadikan penelitian ini sebagai acuan dan evaluasi terhadap proses pelayanan di Kecamatan Jambi Timur. Diharapkan pula rekomendasi yang ada pada penelitian ini digunakan sebagai bahan pertimbangan dalam mengambil keputusan di masa mendatang khususnya pada sistem pelayanan Kecamatan Jambi Timur dan pihak yang terlibat.

Bagi penelitian selanjutnya disarankan untuk mengukur process capability menggunakan atribut dan rating di setiap level sesuai dengan ISO/IEC 15504 di COBIT 5 agar lebih tepat

\section{Daftar Pustaka}

[1] Ayuningdiah, R, 2015. Pengukuran Tingkat Kapabilitas Tata Kelola TI Menggunakan Kerangka Kerja COBIT 5 (Studi Kasus: PT. PDA Net Kota Cirebon). Program Studi Sistem Informasi FTI-UKSW,

[2] Hakim, A., Saragih, H., \& Suharto, A. J. J. S. I., 2014. Evaluasi Tata Kelola Teknologi Informasi Dengan Framework COBIT 5 di Kementerian ESDM. 10(2), 108-117.

[3] ISACA, 2012. COBIT 5: A business framework for the governance and management of enterprise IT: ISACA.

[3] Putra, I. G. L. A. R., Sinaga, B. L., \& Wisnubhadra, I. J. J. B. I, 2015. Evaluasi Tata Kelola Sistem Informasi Akademik Berbasis COBIT 5 di Universitas Pendidikan Ganesha. 6(4).

[4] Saputra, G. Y., Pribadi, F. A., Pribadi, A., \& Setyadi, H. J, 2017. Pengukuran Kinerja Sistem Teknologi Informasi E-Ktp Pada Kantor Kecamatan Pakis Kabupaten Malang Menggunakan Framework Cobit. Paper presented at the Prosiding SAKTI (Seminar Ilmu Komputer dan Teknologi Informasi).

[5] Seeburn, K. 2014. Basic Foundational Concepts Student Book: Using COBIT® 5 In: ISACA.

[6] Sugiyono, P. J. B. A., CV, 2013. Metode Penelitian Manajemen.

[7] ISACA, 2012. COBIT 5: A business framework for the governance and management of enterprise IT: ISACA. 
[8] Selayang Pandang Kecamatan Jambi Timur. Available at: kecjambitimur.jambikota.go.id

[9] Waluyan, G., \& Manuputty, A. D. J. J. T. d. S. I, 2016. Evaluasi Kinerja Tata Kelola TI Terhadap Penerapan Sistem Informasi Starclick Framework COBIT 5 (Studi Kasus: PT. Telekomunikasi Indonesia, Tbk Semarang). 2(3), 157-166 